\begin{tabular}{|c|l|}
\hline Title & Luminescent silicon nanoparticles covered with ionic liquid \\
\hline Author(s) & Miyano, Mari; Wada, Satoshi; Nakanishi, Takay uki; Hasegawa, Y asuchika \\
\hline Citation & $\begin{array}{l}\text { Materials letters, 141,359-361 } \\
\text { https://doi.org/10.1016/.matlet.2014.11.131 }\end{array}$ \\
\hline Issue Date & 2015-02-15 \\
\hline Doc URL & http://hdl.handle.net/2115/58052 \\
\hline Type & article (author version) \\
\hline File Information & Hase text.pdf \\
\hline
\end{tabular}

Instructions for use 


\section{Luminescent Silicon Nanoparticles covered with Ionic}

\section{Liquid}

Mari Miyano, ${ }^{\dagger \ddagger}$ Satoshi Wada, ${ }^{\dagger}$ Takayuki Nakanishi, ${ }^{\dagger}$ Yasuchika Hasegawa, ${ }^{\dagger}$

Faculty of Engineering, Hokkaido University, N13 W8, Kita-ku, Sapporo, Hokkaido 060-8628, Japan, and Bridgestone Corporation, 3-1-1 Ogawahigashi-cho, Kodaira-shi, Tokyo 187-8531, Japan

hasegaway@eng.hokudai.ac.jp

\section{Corresponding author footnote:}

Tel/Fax: +81 117067114

E-mail address: hasegaway@eng.hokudai.ac.jp (Y. Hasegawa)

${ }^{\dagger}$ Faculty of Engineering, Hokkaido University

${ }^{\ddagger}$ Bridgestone Corporation 


\section{ABSTRACT:}

Red-, yellow- and green-luminescent silicon nanoparticles covered with ionic liquid AMImTFSI (1Allyl-3-methylimidazolium bis(trifluoromethanesulfonyl) imide) are reported. Red luminescent silicon nanoparticles (Si-Red), yellow luminescent silicon nanoparticles (Si-Yellow) and green luminescent silicon nanoparticles (Si-Green) were prepared under the acid-etching process using hydrofluoric acid/nitric acid for $50 \mathrm{~s}, 75 \mathrm{~s}$, and $90 \mathrm{~s}$, respectively. Their surface protection using ionic liquid were carried out by the injection of bare silicon nanoparticles into AMImTFSI, resulting in formation of Si-Red-I, Si-Yellow-I and Si-Green-I. The Si-Red-I, Si-Yellow-I and Si-Green-I show effective luminescence after seventeen days. In this study, luminescent silicon nanoparticles covered with ionic liquid are performed for the first time.

KEYWARD: quantum dot, silicon, luminescence, surface protection, Ionic liquid 


\section{Introduction}

Nano-scaled silicon particles are regarded as attractive luminescent materials for use in light-emitting diodes, lasers, solar cells, and bio-sensing applications [1-16]. The silicon nanoparticles are generally prepared from silicon materials or Si compounds. Koshida has reported porous silicon nanolayers prepared by the anodic oxidation of (100)-oriented boron-doped p-type Si wafer $[17,18]$. Seto described the preparation of silicon nanoparticles by laser ablation of a silicon target [19]. Shirahata has reported microemulsion synthesis method of alkoxy passivated silicon nanoparticles [20]. Swihart and Kortshagen prepared silicon nano powders fabricated from $\mathrm{SiH}_{4}$ and $\mathrm{SiCl}_{4}$ gases using laser-induced heating and a non-thermal plasma synthesis [21, 22]. We also reported the novel synthesis and effective surface protection of air-stable luminescent silicon nanoparticles. The silicon nanoparticles are obtained by a novel elimination reaction of carbon monoxide (CO) from $\mathrm{SiO}_{2}$ using a phenol resin at $1900{ }^{\circ} \mathrm{C}$ (Fig. 1a) [23]. Prepared silicon nanoparticles are treated using hydrofluoric acid and nitric acid $\left(\mathrm{HF} / \mathrm{HNO}_{3}\right)$ solutions to control the particle size.

Surface protection on the silicon nanoparticles is a key factor for preparation of brightluminescent materials, because oxidation of bare silicon surface leads to formation of nonluminescent $\mathrm{SiO}_{2}$ compounds, quickly [24]. Various types of surface protection molecules have been reported [25-29]. We recently reported strong-luminescent silicon nanoparticles covered with styrene molecules [23]. Their silicon surface protections are based on the chemical reaction for formation of stable chemical bond between silicon atom and organic molecules, surface termination reaction [23]. The stable chemical bonds on the silicon nanoparticles, however, prevent from surface-exchange reaction for assemble formation and addition of photo-functional groups such as a photosensitizer [30-32]. The surface-exchange reaction is a key factor for development of photo- 
functional materials. Stable protection on the silicon surface without formation of tight chemical bonds is required for improvement of luminescent silicon nanoparticles.

In this study, we focus on ionic liquid as a surface protector of silicon nanoparticles. Ionic liquids are ionic salt-like organic materials $100{ }^{\circ} \mathrm{C}$. Their vapor pressures are extremely low, and they show characteristic wide electrochemical windows, high conductivity and electrolyte properties [33]. Ionic liquids as reaction and extraction solvents have been also reported [34]. Recently, Kuwabata and Torimoto have described effective surface protection performance using ionic liquids on the materials [35]. Ionic liquids have no oxygen and no water that promote oxidation of bare silicon surface. Based on their characteristic properties, we have attempted to use ionic liquids, AMImTFSI (1-Allyl-3-methylimidazolium bis(trifluoromethanesulfonyl) imide) for protection on the silicon nanoparticle surface without surface termination reaction (Fig.1b and c). Luminescence from silicon nanoparticles covered with AMIMTFSI is successfully observed for two weeks. In this study, surface protection and luminescence properties of silicon nanoparticles covered with ionic liquids are demonstrated for the first time.

\section{Experimental}

\section{Materials.}

Tetra-ethoxysilane ES40 as a source for silicon was purchased from COLCOAT CO.LTD. Phenol resin SR-101 as a source of carbon was obtained from AIR WATER INC. Aqueous solution of maleic acid (70 \%) as a catalyst was purchased from Nippon Syokubai. Fluoric acid HF (48 \%) was purchased from Tokyo Chemical Industry Co. Nitric acid $\mathrm{HNO}_{3}$ (62\%) AMImTFSI were purchased Kanto Chemical CO., INC. Polyethylene filter was obtained by Japan Entegris Inc. All other chemicals and solvents were reagent grade and were used without further purification. 


\section{Apparatus}

High-speed shear shredding process is performed using Yoshida Kikai Co. LTD Nano Vita L-ES. Ultrasonic vibration was performed by AS ONE VS-100III. XRD spectra were characterized by a RIGAKU X-ray diffractmeter Smart Lab Ultima U.

\section{Preparation of silicon nanoparticle slurry}

Tetraethoxysilane, phenol resin, and a 30\% aqueous solution of maleic acid were mixed in the ratio of 6:3:1 to prepare the $\mathrm{SiO}_{2}$-sol precursor and heated at $200{ }^{\circ} \mathrm{C}$ for $3 \mathrm{~h}$. By-products (ethanol, water, and formaldehyde) in the $\mathrm{SiO}_{2}$-sol were removed under the chemical reaction. The obtained precursor was subsequently heated at $900{ }^{\circ} \mathrm{C}$ for $2 \mathrm{~h}$ in a nitrogen atmosphere for precarbonization. After pre-carbonization, the precursor was heated at $1900{ }^{\circ} \mathrm{C}$ for $3 \mathrm{~h}$ in an argon atmosphere, which resulted in the formation of silicon nanoparticles covered with $\mathrm{SiO}_{\mathrm{x}}(\mathrm{x}=1$ and 2) and SiC (Fig. 1a).

The slurry of silicon nanoparticles with a small amount of $\mathrm{SiO}_{\mathrm{x}}(8 \mathrm{mg})$ was placed into a polypropylene container with the simultaneous addition of $10 \mathrm{~mL}$ of $48 \% \mathrm{HF}$ and $1 \mathrm{~mL}$ of $68 \%$ $\mathrm{HNO}_{3}$ (Fig. 1b). Acid etching of the silicon nanoparticle slurry was performed under ultra sonication at $20{ }^{\circ} \mathrm{C}$. The acid etching process was monitored by observation of the silicon nanoparticle luminescence under excitation with UV light $(365 \mathrm{~nm})$. The acid-etching process was stopped by the addition of methanol solution (water: methanol $=1: 1 \mathrm{v} / \mathrm{v}, 30 \mathrm{ml}$ ) to the solution. Red luminescent silicon nanoparticles (Si-Red), yellow luminescent silicon nanoparticles (SiYellow) and green luminescent silicon nanoparticles (Si-Green) were prepared under the acidetching process for $50 \mathrm{~s}, 75 \mathrm{~s}$, and $90 \mathrm{~s}$, respectively.

\section{Treatment process using ionic liquid}

After the acid etching process, solution of silicon nanoparticles in $\mathrm{HF} / \mathrm{HNO}_{3}$ was moved to a glove box with a high-purity nitrogen atmosphere. The solution was filtered using a polyethylene 
filter (20nm mesh) and the residue (silicon nanoparticles) was washed with $10 \mathrm{~mL}$ of H2O/Methanol mixture (3/1). The silicon nanoparticles were dried under vacuum at room temperature for $60 \mathrm{~min}$.

Ionic liquid AMImTFSI in glass vessel 5ml was pouring into liquid nitrogen and vacuumdried by the end of bubble disappearing and then moved into a glove box. Prepared silicon nanoparticles were poured into AMImTFSI, and were dispersed under ultra sonication (Fig. 1b). The solution of silicon nanoparticles in AMImTFSI was vacuum-thawed for removal oxygen, methanol and water.

\section{Optical measurements}

UV light source (wavelength at 365nm) was used a LED365-SPT/L (Optocode Corp.) for observation of acid-etching process. The emission spectra of silicon nanoparticles covered with ionic liquid are measured by using a Hitachi High Technologies Co. F-7000.

\section{Results and discussion}

We previously reported that silicon nanoparticles are obtained by the reaction of $\mathrm{SiO}_{2}$ with phenol resins. Prepared silicon nanoparticles were identified using XRD measurements. The diffraction peaks at $2 \theta=28.43,47.33$, and $56.12^{\circ}$ were assigned to the (111), (220), and (311) planes of silicon, that agree well with those of previous silicon nanoparticles [23]. The $\mathrm{SiO}_{2}$ layers on the silicon nanoparticles are removed using hydrofluoric acid (HF), and the size of silicon nanoparticles is also controlled by acid-etching process using $\mathrm{HF} / \mathrm{HNO}_{3}$ (Si-Red, Si-Yellow and SiGreen). Prepared silicon nanoparticles were poured into ionic liquid (AMImTFSI), and were dispersed under ultra sonication (Si-Red-I, Si-Yellow-I and Si-Green-I).

Emission spectra of red, yellow and green luminescent silicon nanoparticles with AMImTFSI (Si-Red-I), (Si-Yellow-I) and (Si-Green-I) are shown in Fig. 2a. These emission bands 
were observed at $608 \mathrm{~nm}, 569 \mathrm{~nm}$ and $545 \mathrm{~nm}$, respectively. Their spectra are different from that of AMImTFSI (emission band at 471nm) as shown in Fig. 2a-4. The luminescence properties of silicon nanoparticles come from the direct recombination of excited electrons and positive holes based on the wavefunction overlap in the nanometer range, which is known as the quantum confinement effect. The energy gaps of silicon nanoparticles depend on their particle sizes, indirect quantum effects of silicon nanoparticles [30].

The emission quantum yield of silicon nanoparticles with surface termination reaction using styrene was found to be 55\%. Emission intensity of Si-Green-I was similar to that of silicon nanoparticles with surface termination. In contrast, that of silicon nanoparticles without surface termination was estimated to be less than $1 \%$. In this study, we successfully observed continuous luminescence from silicon nanoparticles covered with ionic liquid.

Graphical images and their time-dependences of the emission intensities of silicon nanoparticles covered with AMImTFSI are shown in Fig. 2b. Silicon nanoparticles without any surface terminations are rapidly quenched under air. On the other hand, we can not observed the drastic decrease of the emission intensities of Si-Red-I, Si-Yellow-I and Si-Green-I for several hours. The Si-Red-I, Si-Yellow-I and Si-Green-I dispersions show effective luminescence after seventeen days. Their relative emission intensities based on the fresh-made silicon nanoparticles (100 \%) are estimated to be over $20 \%$. We consider that ionic liquids promote effective protection from oxidation and/or impurity adsorptions of bare silicon surface. The silicon nanoparticles covered with ionic liquid can be easily exchanged using various types of functional organic molecules, which are not able to react on the silicon surface with surface protection such as styrene molecule. Dispersion of silicon nanoparticles in ionic liquid is expected to be useful as novel luminescent materials for future photonic applications. 


\section{Conclusions}

In this study, we demonstrated effective luminescent dispersion of silicon nanoparticles covered with ionic liquid. The silicon nanoparticles with ionic liquid exhibit perfect Si-H bonds on the surface without stable chemical bonds [30]. From this point, silicon nanoparticles with ionic liquid also expected to use as not only luminescent materials, but catalysis for chemical reaction. By using TEM (transmittance electron microscope) or SEM (Scanning electron microscope) techniques [36]. We would observe directly the $\mathrm{Si}-\mathrm{H}$ surface of the luminescent silicon nanoparticles with ionic liquid. Those surface observations of silicon nanoparticles are linked with study on solid-state physics of silicon nanomaterials. The silicon nanoparticles with ionic liquid are new materials for development of bright luminescent nanomaterials.

\section{AUTHOR INFORMATION}

\section{Corresponding Author}

hasegaway@eng.hokudai.ac.jp

\section{REFERENCES}

[1] Joel AK, Jonathan GCV. An Investigation into near-UV Hydrosililation of Freestanding A Silicon Nanocrystals. J G C ACS NANO 2010;4:4645-4656.

[2] Rhett JC, Michael KMD, Jonathan GCV. Exploration of Organic Acid Chain Length on WaterSoluble Silicon Quantum Dot Surface. Langmuir 2010; 26:19:15657-15664.

[3] Hua F, Swihart TM. Ruckenstein, E. Efficient Surface Grafting of Luminescent Silicon Quantum Dots by photoinitiated hydrosililation. Langmuir 2005;21:6054-6062.

[4] Takeoka S, Fujii M, Hayashi S. Size-dependent photoluminescence from surface-oxidized Si nanocrystals in a weak confinement regime. Phys Rev B 2000;62:16820-16825. 
[5] Linyou C, Pengyu F, Barnard SE, Brown MA., Brongersma LM. Tuning the Color of Silicon Nanostructures. Nano Lett 2010;10:2649-2654.

[6] Llansola Portolés JM, Dies PR, Dell’Arciprete LM, Caregnato P, Romero JJ, Mártire OD, Azzaroni O, Ceolin M, Gonzalez CM. Understanding the parameters Affecting the Photoluminescence of Silicon Nanoparticles. J Phys Chem C 2012;116:11315-11325

[7] Yang Z, Dobbie RA, Cui K, Veniot GCJ. A Convenient method for preparing AlkylFunctionalized Silicon nanocubes. J Am Chem Soc. 2012;134:13958-13961.

[8] Mastronardi LM, Hennrich F, Henderson JE, Maier-Flaig F, Blum C, Reichenbach J, Lemmer U, Kübel C, Wang D, Kappes MM, Ozin AG. Preparation of monodisperse Silicon Nanocrystals using Density Gradient Ultracentrifugation. J Am Chem Soc. 2011;133:11928-11931.

[9] Li Q, He Y, Chang J, Wang L, Chen H, Tan Y, Wang H, Shao Z. Surface-modified Silicon nanoparticles with Ultrabright Photoluminescence and Single-Exponential Decay for nanoscale Fluorescence lifetime Imaging of temperature. J Am Chem Soc 2013;135:14924-14927.

[10] Shiohara A, Hanada S, Prabakar S, Fujioka K, Lim HT, Yamamoto K, Northcote TP, Tilley D R. Chemical Reactions on Surface Molecules Attached to Silicon Quantum Dots. J Am Chem Soc 2010;132:248-253.

[11] Manhat AB, Brown LA, Black AL, Alexander Ross BJ, Fichter K, Vu T, Richman E, Goforth MA. One-Stem melt Synthesis of Water-Soluble, Photoluminescent, Surface-Oxidized Silicon nanoparticles for Cellular Imaging applications. Chem Mater 2011;23:2407-2418.

[12] Sato S, Swihart TM. Propionic-Acid-Terminatied Silicon Nanoparticles: Synthesis and Optical Characterization. Chem Mater 2006;18:4083-4088.

[13] Watanabe A. Optical properties of polysilanes with various silicon skeletons. J Organomettalic Chem 2003;685:122-133

[14] Furukawa S, Miyasato T. Quantum size effects on the optical band gap of microcrystalline Si:H Phsy Rev B 1988;38:5726-5729 
[15] Brus L. Luminescence of Silicon Materials: Chains, Sheets, Nanocrystals, Nanowires, Microcrystals, and Porous Silicon. J Phys Chem 1994;98:3575-3581

[16] Saitow K, Yamamura T. Effective Cooling Generates Efficient Emission: Blue, Green, and red Light-Emitting Si Nanocrystals. J. Phys. Chem. C 2009; 113:8465-8470

[17] Koshida N, Matsumoto N. Fabrication and quantum properties of nanostructured silicon. Mater Sci \& Eng 2003; R40:169-205.

[18] Gellos B, Koshida N. Highly Efficient and a Stable Photoluminescence of nanocrystalline Porous Silicon by Combination of Chemical Modification and Oxidation under High Pressure. Jpn J Appl Phys 2007;40:2429-2433.

[19] Seto T, Kawakami Y, Suzuki N, Hirasawa M, Aya N. Laser Synthesis of Uniform Silicon Single Nanodots. Nano Lett 2001;1: No.6:315-318.

[20] Shirahata N, Hasegawa T, Sakka Y, Tsuruoka T. Size-tunable UV-Luminescent Silicon Nanocrystals. Small 2010;8:915-921

[21] Li X, He Y, Talukdar SS, Swihart MT. Process for Preparing Macroscopic Quantities of Brightly Photoluminescent Silicon nanoparticles with Emission Spanning the Visible Spectrum. Langmuir 2003;19:8490-8496.

[22] Mangolini L, Jurbergs D, Rogojina E, Kortshagen U. High efficiency photoluminescence from silicon nanocrystals prepared by plasma synthesis and organic surface passivation. Phys Stat Sol (c) 2006;3:(11):3975-3978.

[23] Miyano M, Endo S, Takenouchi H, Nakamura S, Iwabuti Y, Shiino O, Nakanishi T, Hasegawa Y, Novel Synthesis and Effective Surface Protection of Air-Stable Luminescent Silicon Nanoparticles. J Phys Chem C 2014;118:19778-19784.

[24] Harper J, Sailor JM. Photoluminescence Quenching and the Photochemical Oxidation of Porous Silicon by Molecular Oxygen. Langmuir 1997;13: 4652-4658 
[25] Biestam W, Lagen BvB, Gevaert SV, Marcelis TMA, Paulusse MJJ, Moelen WFM, Zuilhof H. Pre parathion, Characterization, and Surface Modification of Trifluoriethyl Ester-Terminated Silicon Nanoparticles. Chem Mater 2012;24:4311-4318

[26] Buriak MJ. Illuminating Silicon Surface Hydrosililation: An Unexpected Plurality of Mechanisms. Chem Mater 2014;26:763-772

[27] Romero JJ, Llansola-Portolés JM, Dell’Arciprete ML, Rodriguez B H, Moore LA, Gonzalez CM. Photoluminescent 1-2nm Sized Silicon Nanoparticles: A Surface-Dependent System. Chem mater 2013; 25: 3488-3498

[28] Okamoto H, Kumai Y, Sugiyama Y, Mitsuoka T, Nakanishi K, Ohta T, Nozaki H, Yamaguchi S, Shirai S, Nakano H. Silicon Nanosheets and Their Self-Assembled regular Stacking Structure. J Amer Chem Soc 2010;132:2710-2718

[29] Okamoto H, Sugiyama Y, Nakano H. Synthesis and Modification of Silicon Nanosheets and Other Silicon Nanomaterials.Chem Eur J 2011;17:9864-9887

[30] Kawashima A, Nakanishi T, Shibayama T, Watanabe S, Fujita K, Tanaka K, Koizumi H, Fushimi K, Hasegawa Y. Enhanced Magneto-optical Properties of Semiconductor EuS nanocrystals Assisted by Surface Plasmon Resonance of Gold Nanoparticles. Chem Eur J 2013;19:14438-14445

[31]Tanaka A, Kamikubo H, Doi Y, Hinatsu Y, Kataoka M, Kawai T, Hasegawa Y. Self-Assembly and Enhanced Magnetic Properties of Tree-Dimensional Superlattice Structure Composed of Cube-Shaped EuS nanocrystals. Chem Mater 2010;22:1776-1781

[32] Kawashima A, Nakanishi T, Fushimi K, Hasegawa Y. EuS Nano-assembles Linked with Photofunctional Naphthalenedithiols. Mol Cryst Liq Cryst 2013;579:1-8

[33] Zhang X, Liang M, Ernsting PN, Maroncelli M. Conductivity and Solvation Dynamics in Ionic Liquids. J Phys Chem Lett 2013;4:1205-1210, 
[34] Welton T. Room-Temperature Ionic liquids. Solvents for Synthesis and Catalysis. Chem Rev 1999;99:2071-2083

[35] Torimoto T, Okazaki K, Kiyama T, Hirahara K, Tanaka N, Kuwabata S. Sputter deposition onto ionic liquids : Simple and clean synthesis of highly dispersed ultrafine metal nanoparticles Appl Phys Let 2006; 89:243117

[36] Torimoto T, Okazaki K, Kiyama T. Sputter deposition onto ionic liquids: Simple and clean synthesis of highly dispersed ultrafine metal nanoparticles. Appl Phys Lett 2006;89:243117-13.

\section{Figure Captions}

Figure 1. Systematic procedures for silicon nanoparticles covered with ionic liquid. a) Synthesis of silicon particles in SiOx. b) Acid-etching process and preparation of silicon nanoparticles covered with ionic liquid. c) Chemical structure of ionic liquid: AMImTFSI

Figure 2 a) Emission spectra of silicon nanoparticles covered with ionic liquid, Si-Red-I (1: triangles), Si-Yellow-I (2: circles), Si-Green-I (3: squares), and AMImTFSI (4: gray). b) Timedependence of the emission intensities of Si-Red-I (1: triangles), Si-Yellow-I (2: circles) and SiGreen-I (3: squares). Inset: graphical picture of luminescent Si-Red-I (1), Si-Yellow-I (2) and SiGreen-I (3). 
M. Miyano et al., Figure 1

a)

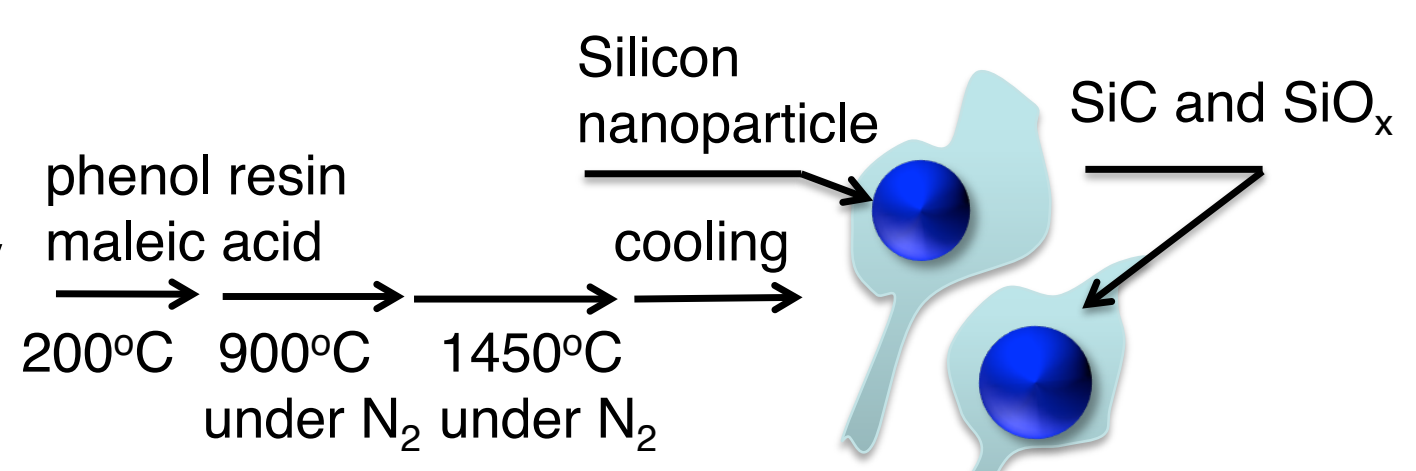

b)

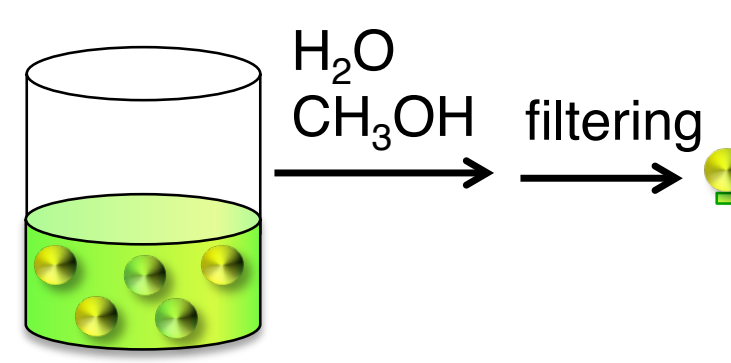

Silicon nanoparticles with $\mathrm{HF} / \mathrm{HNO}_{3}$

for control of particle size

c)

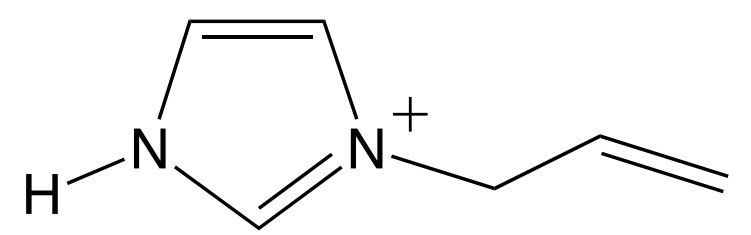

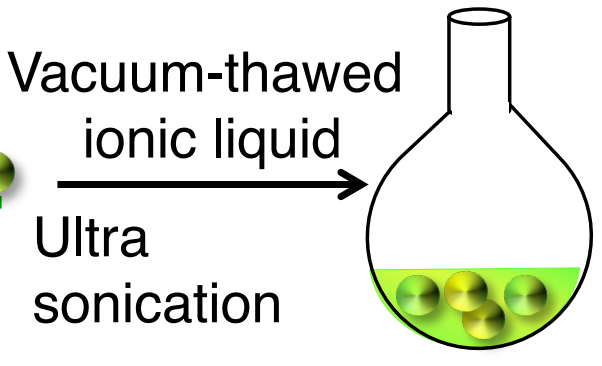

Si nanoparticles covered with ionic liquid 
M. Miyano et al., Figure 2
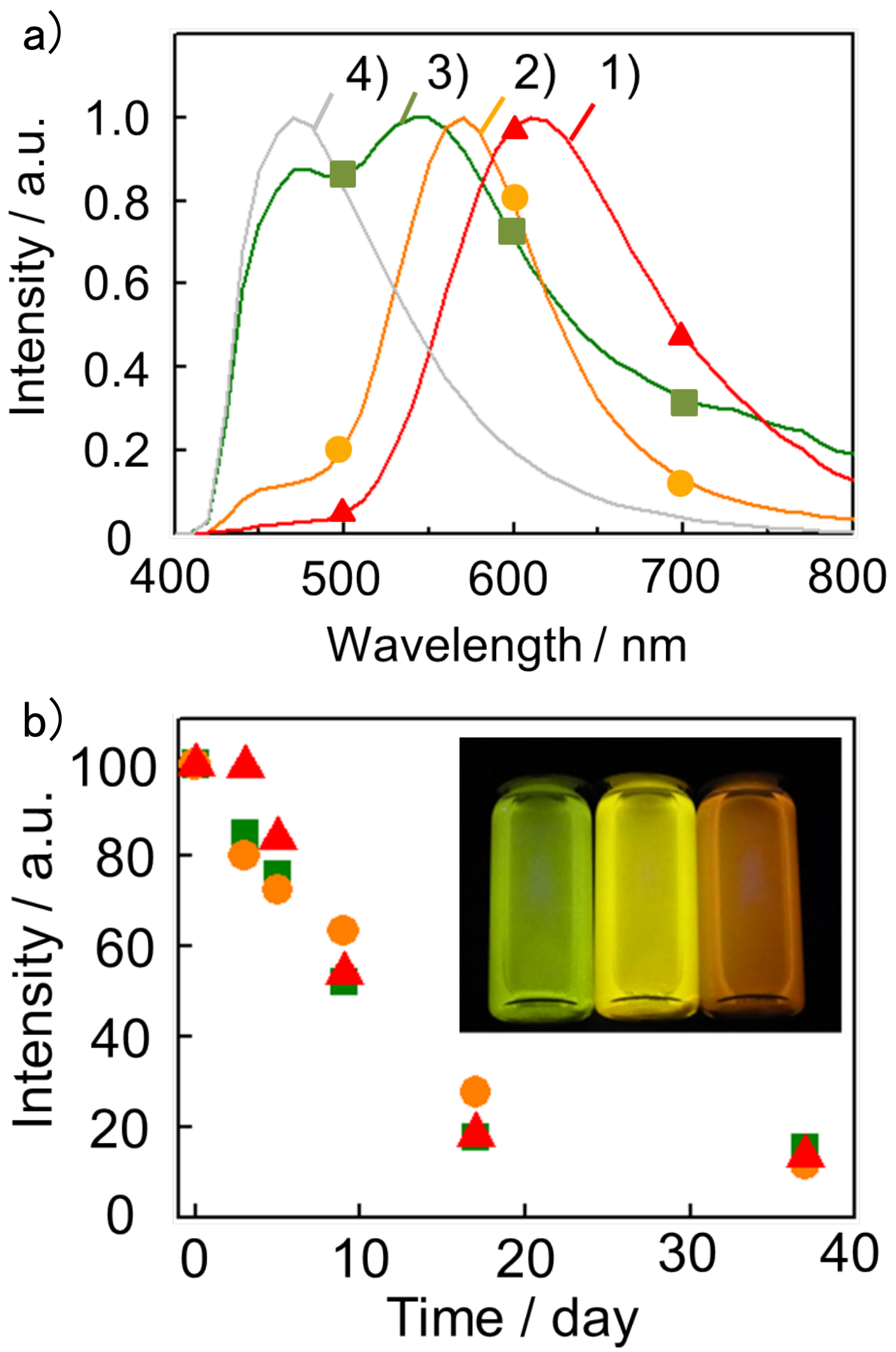